\section{BMJ Paediatrics Open}

\title{
Neonatal and perinatal palliative care pathway: a tertiary neonatal unit approach
}

\author{
Abena N Akyempon (D) , ${ }^{1}$ Narendra Aladangady ${ }^{1,2}$
}

\begin{abstract}
To cite: Akyempon AN, Aladangady N. Neonatal and perinatal palliative care pathway: a tertiary neonatal unit approach. BMJ Paediatrics Open 2021;5:e000820. doi:10.1136/ bmjpo-2020-000820
\end{abstract}

Received 14 August 2020 Revised 24 November 2020 Accepted 14 December 2020
Check for updates

(c) Author(s) (or their employer(s)) 2021. Re-use permitted under CC BY-NC. No commercial re-use. See rights and permissions. Published by BMJ.

${ }^{1}$ Neonatology, Homerton University Hospital NHS Foundation Trust, London, UK ${ }^{2}$ Pediatrics, Centre for Paediatrics, Bart's and the London School of Medicine and Dentistry, London, UK

Correspondence to Professor Narendra Aladangady; n.aladangady@nhs.net

\section{ABSTRACT}

A lack of well-structured guideline or care pathway results in inadequate, inconsistent and fragmented palliative care (PC) for babies and their families. The impact on the families could be emotionally and psychologically distressing. Not all neonatal units have specialist PC clinicians or teams, and such units will benefit from a well-planned perinatal PC pathway. In this article, we discuss a tertiary neonatal unit perinatal care pathway which provides guidance from the point of diagnosis and establishment of eligibility of a baby for PC through to care after death and bereavement support for families. Planning PC with families which encourages family-centred and individualised approach is also discussed.

\section{INTRODUCTION}

WHO defines palliative care (PC) as an approach that improves the quality of life of patients (adults and children) and their families who are facing problems associated with life-threatening illness. It prevents and relieves suffering through the early identification, correct assessment and treatment of pain and other problems, whether physical, psychosocial or spiritual. ${ }^{1}$ WHO also recommends that PC for children begins when lifelimiting illness is diagnosed and continues regardless of whether the child receives treatment directed at the disease and it involves giving support to the family and including them in decision making regarding the $\mathrm{PC}$ needs of the child. ${ }^{2}$ This approach to children's PC is adopted by other professional groups and charity organisations. ${ }^{34}$

Parallel model of care is the practice where curative or disease directed treatment and PC are concurrently implemented where appropriate. $^{5}$ Depending on clinical progression of baby, a shift from curative measures to PC occurs. With this approach, PC is initiated without delay and is not confined to end of life but incorporated throughout the disease process as part of continuum of care. Parallel care takes into consideration of planning for potential survival while also considering plans for deterioration or death. This encourages

\section{Key messages}

Palliative care (PC) aims to keep babies comfortable by treating distressing symptoms, avoiding unnecessary monitoring and futile treatment that prolongs suffering of babies and families.

- Parallel care planning should be the core component of PC for babies because it gives the opportunity to review care plans according to disease progression.

- The focus of PC is to support and enable parents and family as partners of the multidisciplinary team in decision making regarding baby's care.

- Provision of emotional, psychological and spiritual support for families fosters good relationship between staff and family and enables to heal parental grief and pain.

- Compassionate communication and information sharing that respects the sociocultural beliefs and values of parents have significant bearing on parental participation in PC process.

- Staff members should be aware of principles of PC and care pathways, which will promote provision of quality PC to all eligible babies and families.

open discussion about the families wishes. The National Institute for Health and Care Excellence in the UK recommends parallel care planning as an essential core element of PC for the paediatric population. ${ }^{7}$ Parallel care gives clinical staff and the family the opportunity to review care plans of the baby according to the disease progress and needs. Also parents and family are spared the sense of abandonment and anxiety when curative measures are stopped suddenly and PC initiated when the baby's condition deteriorates and death becomes imminent. Parents are more likely to agree with the decision to redirect care to palliation if they feel options for disease directed treatment have been exhausted. ${ }^{5}$ However, it is also acknowledged that there are clinical conditions where curative treatment and even disease modifying treatment do not exist and PC may be the only option. 
In recent times, neonatal and perinatal PC has attracted a lot of interest and many leading specialist professional groups in different countries have put forward recommendations and adopted guidelines on how to deal with such cases. ${ }^{8-12}$ Although the fundamental principles for all these guidelines are similar, there are no evidencebased empirical studies to indicate the best model of care. $^{13}$

The World Health Assembly proceedings reported in 2014 acknowledged that inadequate integration of PC into health and social care systems is a major contributing factor to the lack of equitable access to such care. Recommendations were made for member states to develop, strengthen and implement evidence-based integrated PC policies across all levels of care with emphasis on primary care, community and home-based care. ${ }^{14}$ Although this has been reiterated by many reports and research findings in this field, ${ }^{15-17}$ others have suggested that integration of PC into regular healthcare and convincing the wider professional community will not be an easy task. Meanwhile, standardisation of PC into education, referral pathways, protocols and guidelines and standardised information exchange may need to be enhanced. ${ }^{15}$

den Herder-van der Eerden et al reporting on the perspective of leaders from seven European countries on integration of PC found out that at the clinical level where multidisciplinary teams stimulate early referral of patients with PC needs and coordinate functions to ensure continuity of care, integration of PC has most likely succeeded. ${ }^{17}$

Hence at the clinical level, the implementation of integrated perinatal PC can be addressed by formulating guidelines and care pathways with multidisciplinary team (fetal medicine, obstetricians, neonatologist, nurses, midwives, family doctor/general practitioner,) input. This should include a clear referral pathway for the support of specialist PC teams and other services such as hospices, pastoral care and counselling for families. A comprehensive and appropriate means to share information so that there will be no need for parents to repeat their history at every stage or contact with health professionals is also essential.

A national survey carried out to examine the quality of PC provided by tertiary neonatal units (NU) in the UK highlighted the fact that some units did not have wellstructured PC pathway or guidelines, neither did they have organised PC teams. ${ }^{18}$ Reports from different parts of the world have also acknowledged the fact that the provision of neonatal and perinatal PC are inconsistently offered as part of healthcare. ${ }^{19}{ }^{20}$ Better integration of services will hopefully address this problem. In NU where there are no PC teams or established perinatal PC pathways or guidelines, the provision of this service becomes a challenge. Lack of staff education and training is also recognised as an obstacle to the provision of high standard neonatal and perinatal PC. ${ }^{21}$ Providing structured educational programmes for both nursing and medical trainees will improve the standard of care. ${ }^{22-24}$
In the UK, three very important professional groups, British Association of Perinatal Medicine, Royal College of Paediatrics and Child Health and General Medical Council have issued guidelines on neonatal and perinatal PC. ${ }^{9} 1025$ This is expected to create increased awareness among professionals in neonatology, obstetrics and fetal medicine who may be involved in decision making about end-of-life care for neonates and unborn babies around perinatal period. Care pathways use multidisciplinary guidelines to develop and implement clinical plans which represent current local best practice for specific conditions. ${ }^{26}$ Based on the recommendations of these professional bodies ${ }^{91025}$ and review of the literature, ${ }^{811} 1327$ a clinical neonatal and perinatal PC pathway that has been developed for a tertiary NU, Homerton University Hospital NHS Trust, is presented and discussed in this article.

The Homerton University Hospital NU is one of the largest medical tertiary NUs in England. It is one of the three tertiary NUs in the North Central and East London Neonatal Network. The Homerton NU has 46 cots (16 intensive care, 8 high dependency and 22 special care cots). In addition, there are 8 Transitional Care cots (outreach model). Average admission to the unit is around 950 babies per year. The Hospital has a regional fertility unit, fetal medicine unit and the maternity unit, has around 6000 deliveries per year.

\section{BACKGROUND}

Neonatal and perinatal medicine have gone through significant advancement because of the application of new and modern scientific medical and diagnostic technologies. This has resulted in improved survival; however, some new-born infants still die either because of extreme prematurity, medical complications or congenital abnormality. In 2016, congenital abnormalities accounted for $34 \%$ of new-born deaths in the UK and it was the second most common cause of death. ${ }^{28}$ Prenatal diagnosis of congenital abnormalities is now made early in pregnancy and termination of pregnancy is offered as an option. Breeze et al reported that about $40 \%$ of parents faced with diagnosis of lethal fetal abnormality choose to continue the pregnancy. ${ }^{29}$ However, some of these infants with lethal abnormalities will not survive the peripartum process or will succumb immediately or later after delivery. It is an ethical and moral responsibility of professionals to support such infants and their parents hence the need for appropriately planned PC that will suit the need of every case. Likewise, termination of pregnancy for fetal abnormality has profound psychological trauma on those involved and provision of emotional support before and after the procedure is reported to be beneficial to women. ${ }^{30} 31$

Various reports indicate that most neonatal deaths occur in the hospital setting following planned withdrawal or limitation of life sustaining treatment (LST). ${ }^{32} 33 \mathrm{~A}$ study of decision making and modes of death in our unit 
by Roy et al reported that nearly all Caucasian parents but only $54 \%$ of Black African parents agreed to withdrawal of LST, with religious and personal beliefs accounting for the difference between the two groups. ${ }^{33}$ The importance of ethnic, cultural and religious beliefs and practices in relation to the outcome of discussions regarding withdrawal LST cannot be overemphasised. In clinical setting sometimes the discussions between professionals and families are prolonged and the window of opportunity for withdrawal of LST to be followed by imminent death is missed or some infants will survive despite limiting LST. $^{34}$ Parents and families facing this situation will need emotional and psychological support as well as appropriate comfort care in the form of palliation for their newborn infant. This service is best provided by PC specialist teams or trained healthcare staff in a multidisciplinary team but where this is not available, the use of a multidisciplinary formulated guidelines and/or care pathway will ensure timely provision of PC to end-of-life care that is of acceptable standard.

\section{Developing the PC pathway}

Although the NU was providing PC to babies and their families over the years, unfortunately there was no unit approved written guidelines. A consensus decision was taken by the clinical team to develop this care pathway. This decision also fulfilled the recommendations of professionals bodies and neonatal charity groups. ${ }^{9}{ }^{10} \mathrm{It}$ also addressed the requirement of Department of Health England, ${ }^{35}$ in terms of supporting parents and families throughout hospitalisation of their babies. Three members of staff (two neonatal doctors and one neonatal nurse specialist in counselling and bereavement) took the lead in developing the guidelines in consultation with all neonatal doctors, nurses, allied health professionals (AHP), obstetric doctors, midwives and bereavement specialist midwives. We take regular parents' feedback and their suggestions were incorporated in developing PC pathway where possible. The guideline was discussed at departmental clinical governance meeting represented by the neonatal and perinatal team before it was formally approved.

In order to provide the best possible care, there is regular teaching for staff on PC every 6 months, and patient feedback is obtained for quality improvement purposes.

\section{The team providing $\mathrm{PC}$}

The NU PC team as outlined in figure 1 below is made up of a named clinician, named nurse responsible for PC, bereavement specialist, psychologist or counsellor, chaplain or pastoral care team, AHP (eg, physiotherapist) parents and obstetric team when appropriate.

The rapid response perinatal PC team is made up of obstetric/fetal medicine consultant, specialist midwife, Bereavement midwife, chaplain/pastoral care team (where appropriate), counsellor/psychologist, neonatal consultant, genetic counselling team and parents.
Figure 1 shows Perinatal PC pathway which is used in our tertiary NU. The discussion of the details below is based on the recommendations of professional bodies.

\section{Establishing eligibility for PC}

Establishing eligibility of the fetus or neonate for PC should be based on the best possible information on the diagnosis and prognosis of the underlying condition. This may require input from a multidisciplinary team of clinical specialists and joint decision making with parents. Shared decision making with parents regarding PC for their baby should occur in a manner that will ensure parents feel fully involved in the decision-making process of initiation and provision of PC. ${ }^{36}$ Transparency in sharing information and good relationship between healthcare professionals and parents must be developed from the onset and during the course of baby's hospitalisation. ${ }^{37} \mathrm{PC}$ should be discussed with parents and family when the diagnosis, either antenatally or postnatally, has been confirmed to be incompatible with life. Also, PC can be considered for fetuses and babies with conditions that are not compatible with long term survival, that carry significant risk of death, impairment of quality of life, or that cause unbearable suffering. The eligibility of a neonate for PC can be considered in five broad categories $^{9}$ (see table 1 ).

\section{Breaking news}

As shown in figure 1, following establishment of eligibility for PC before or after birth, the next stage is to update parents with the information about their loved one.

The process of delivering bad news to parents has a significant impact on the physician/parent relationship and the satisfaction of the parents and their family in relation to the healthcare team and PC system. ${ }^{38}$ Every family should receive the disclosure of their baby's prognosis in a face-to-face discussion in privacy and should be treated with respect, honesty and sensitivity. Information should be provided for the family using language that they can understand; they should be given enough time to assimilate the information and to discuss it with their wider family or friends if they wish to. Further discussions can be arranged as and when necessary. All discussions and the agreed outcome including whether they wish to consider PC or not should be explicitly documented.

\section{Planning PC with families}

Healthcare providers are encouraged to model effective, compassionate communication that respects parents and family cultural beliefs and values and to promote shared decision making such that parents will not feel overburdened or denied of full participation in any decision relating to the care of their baby. ${ }^{36} 39$ The approach to communication by clinicians has significant bearing on parental participation in this shared decision making. Shaw et al reported on two distinct communicative approaches to decision-making used by doctors: 'making recommendations' and 'providing options. ${ }^{36}$ Parents 
1. ESTABLISHING ELIGIBILITY FOR PALLIATIVE CARE BEFORE OR AFTER BIRTH

2. BREAKING NEWS

3. REFERRAL TO RAPID RESPONSE PERINATAL PALLIATIVE CARE TEAM

Obstetric/fetal medicine consultant, specialist midwife, bereavement midwife, chaplain/pastoral care team (where appropriate), counsellor/psychologist, neonatal consultant, genetic counselling team and parents

4. NEONATAL PROFESSIONAL MULTIDISCIPLINARY TEAM

A named clinician, named nurse for PC, bereavement specialist, counsellor/ psychologist, chaplain/pastoral care team, AHPs (e.g. physiotherapist) and parents (obstetric team when appropriate)

5. END OF LIFE CARE PLANNING

- Multidisciplinary assessment of care options and family needs.

- Parents should be given the name and contact details of a key member of staff

- Discuss with parents and offer memory box as per unit guidelines and 'remember my baby' photo service if parents are interested

INMINENT DEATH

Babies in ITU or delivery suite expected to live less than 24 hours.

Agreed care plan, from active or supportive care to end of life care, should be discussed with the family and documented in the baby's notes Discussion about post-mortem examination where relevant and organ donation when appropriate
NON-IMMINENT DEATH

Discuss supportive care to end of life care with parents and offer referral.

All discussions and agreed care

plan should be documented in the babv's notes'

1

Referral to paediatric palliative care services for advice Transfer to hospice services as appropriate or Discharge for home care with Paediatric and neonatal community nurse team support

\section{CARE AFTER DEATH}

- Confirmation and certification of death

- Discuss with parents and offer memory box and 'remember my baby' photo service $*$ if not previously discussed

- Bereavement support as per local neonatal unit guidelines and policy

Figure 1 Neonatal and perinatal palliative care (PC) pathway. AHP, allied health professionals.

feel constrained when presented with recommendations usually based on the decision of attending clinical team. This may result in disagreement between parents and clinical team. However, when a list of options is provided to parents, they become more engaged and it makes them feel part of the decision-making process. This will most likely help in alleviating the difficulties of child loss faced by parents in this situation. Multiagency assessment of the needs of the parents and their family with regards to providing emotional, psychosocial, medical and spiritual

\section{Table 1 Categories of neonates who may be eligible for PC}

\begin{tabular}{lll}
\hline Category & Criteria & Example of cases \\
\hline 1 & $\begin{array}{l}\text { Antenatal/postnatal diagnosis of a condition that is not compatible with } \\
\text { long-term survival. }\end{array}$ & Bilateral renal agenesis anencephaly. \\
\hline 2 & $\begin{array}{l}\text { Antenatal/postnatal diagnosis of a condition which carries a high risk of } \\
\text { significant morbidity or death. }\end{array}$ & $\begin{array}{l}\text { Severe bilateral hydronephrosis with impaired renal } \\
\text { function. } \\
\text { Severe spina bifida. }\end{array}$ \\
\hline 3 & $\begin{array}{l}\text { Babies born at the margins of viability where intensive care has been } \\
\text { deemed inappropriate. }\end{array}$ & $\begin{array}{l}\text { Babies born at } \leq 23 \text { weeks with bilateral } \\
\text { haemorrhagic parenchymal infarct. }\end{array}$ \\
$\begin{array}{l}\text { Postnatal clinical conditions with a high risk of severe impairment of quality } \\
\text { of life and when the baby is receiving life support or may at some point } \\
\text { require life support. }\end{array}$ & $\begin{array}{l}\text { Severe hypoxic ischaemic encephalopathy. } \\
\text { Postnatal conditions which result in the baby experiencing 'unbearable } \\
\text { suffering' in the course of their illness or treatment. }\end{array}$ & Severe necrotising enterocolitis. \\
\hline 5
\end{tabular}

$\mathrm{PC}$, palliative care. 
support is very important and should be considered as soon as possible after their baby's diagnosis or prognosis has been confirmed.

Referral to Rapid Response Perinatal PC team (see figure 1) is initiated where antenatal diagnosis of a lethal congenital abnormality has been made. The parents are counselled about the diagnosis and prognosis of the condition, options of management care plan for the unborn baby and the mother and are supported by the team to make a well-informed decision. Some parents will opt for termination of pregnancy. If the decision is to continue the pregnancy till delivery, then postdelivery care of the baby needs to be planned with the family. As per the care pathway (figure 1), where imminent death is expected within 24 hours, the parents and family may decide to be with the baby in a private room on the delivery suite for end-of-life comfort care. A neonatologist examines the baby and documents findings either before or after death depending on baby's clinical condition taking family wishes into consideration. Where baby remains alive for several hours and parents prefer, the baby may be transferred to the NU for supportive and comfort care.

Conflicts and disagreements may occur between parents, families, and healthcare professionals especially regarding care plan. This can be emotionally stressful and challenging, timely intervention can prevent breakdown of trust between all parties. ${ }^{1041}$ All efforts should be made in bringing about resolution of any disagreements. Giving enough time for parents to come to terms with the situation, further communication with parents, as well as shared decision making are very helpful in resolving such problems. Seeking second medical opinion from a healthcare professional from another hospital may be considered. ${ }^{10}$ Also, a mediation service can be of great help if difficulties in resolving the conflict continue. ${ }^{4243} \mathrm{As}$ much as possible legal action should be avoided, however it may be considered in the best interest of the baby if all options are exhausted. ${ }^{44}$

Postnatal care plan following antenatal or postnatal eligibility Planning for the care of the baby's needs should include provision of hydration and nutrition, pain relief and comfort care as well as management and control of all other symptoms to maintain the comfort and dignity of the infant. All babies eligible for PC (non-imminent death as shown in the care pathway-see figure 1) are initially managed on the NU. Early referral and involvement of specialist PC team for advice is very helpful and highly recommended. Investigations should only be performed if the results might lead to treatment that will improve the baby's quality of life or help with the diagnosis and management of subsequent pregnancies. Monitoring of the baby is not necessary but may be used if helpful for parents. The appropriate place for care and death, either in hospital setting, hospice or at home should be discussed, and the family should be assessed for any necessary support. Discussions and agreed components of the PC plan should be documented in the notes and shared with the relevant hospital staff and community teams at both local and referring centre when appropriate. Parallel planning for transition periods into and out of active, supportive and end-of-life care should be discussed with the family and clearly documented in the care plan. Limitations to resuscitation should be discussed, documented and regularly reviewed. Comfort and dignity of the baby should be maintained. Parents should be offered choices of how they would like to spend time with their baby and offered the option to create and collect mementoes. At all times, the parents should have the name and contact details of a key member of staff whom they can contact when necessary.

\section{End-of-life care planning}

Parents and families should be helped to prepare an end-of-life plan for their baby if they wish to do so and should be provided with care and support to achieve this. The named or attending consultant neonatologist should discuss with the parents where the baby will be cared for, explain what is likely to happen, and take their wishes into account as far as possible. Provision of PC and end-of-life care at home is possible with the support of community nurses and PC team where parents prefer. The agreed care plan from active or supportive care to end-of-life care should be explained to the family and care delivery team (eg, how and when an ET tube and intravenous cannula are removed, and monitoring leads disconnected). Physical changes that are likely to occur as a baby dies should be discussed with the parents and family. They should be offered the chance to see, hold and spend time with their baby while he or she dies and/ or after death. To ensure privacy a dedicated room or space where parents and family will spend time together with the baby during and after death is essential.

Professional support should always be made available during end-of-life care. If relevant, the parents should be told about the option of organ donation. A senior member of staff should sensitively encourage the parents to consent to a postmortem investigation where relevant (in some cases it may be appropriate to discuss this sensitively in the antenatal period).

\section{Care after death}

Bereavement support should be provided and continue throughout the baby's death and beyond. Staff should share contact details of the relevant charities such as Stillbirth and neonatal death charity which offer care and support to bereaved parents. Parents should be offered a follow-up appointment so they can have the opportunity to discuss relevant events, any unanswered questions about their baby's condition and care as well as postmortem findings where applicable.

\section{Auditing PC practice}

There should be regular audit of the care pathway implemented to assess the quality of care provided. 
The following areas should be audited:

- PC clinical skills and training details of staff members should be maintained and reviewed annually.

- Adherence to PC guideline practice.

- Details of documentation of parent communication and support provided to family.

- Regular survey of parents and staff feedback on quality of PC service provided, and parents and family satisfaction.

- Staff training and their confidence in providing PC.

\section{CONCLUSION}

This is a simplified but comprehensive care pathway which is easy to use in most clinical scenarios where neonatal and perinatal PC is being considered for a baby and the family. It has the benefit of ensuring timely and consistent provision of PC. It helps in coordinating and facilitating the activities of the multidisciplinary team for the purpose of providing ongoing care from the time of diagnosis and establishment of eligibility for PC for the baby till end-of-life care as well as support for the family after the death of the baby. It also can be used for education and training of both medical and nursing staff.

Contributors ANK developed the guideline, wrote the first draft of the manuscript, edited and approved final manuscript. NA conceptualised and contributed to development of guideline, edited and approved the final manuscript.

Funding The authors have not declared a specific grant for this research from any funding agency in the public, commercial or not-for-profit sectors.

\section{Competing interests None declared.}

Patient and public involvement Patients and/or the public were not involved in the design, or conduct, or reporting, or dissemination plans of this research.

Patient consent for publication Not required.

Ethics approval The guideline was reviewed and approved by the Hospital clinical governance team so that every stakeholder will take appropriate responsibility.

Provenance and peer review Not commissioned; externally peer reviewed.

Data availability statement № data are available. No data were collected for this manuscript.

Open access This is an open access article distributed in accordance with the Creative Commons Attribution Non Commercial (CC BY-NC 4.0) license, which permits others to distribute, remix, adapt, build upon this work non-commercially, and license their derivative works on different terms, provided the original work is properly cited, appropriate credit is given, any changes made indicated, and the use is non-commercial. See: http://creativecommons.org/licenses/by-nc/4.0/.

ORCID iD

Abena N Akyempon http://orcid.org/0000-0002-1873-8746

\section{REFERENCES}

1 World Health Organisation. Palliative care, 2020. Available: https:// www.who.int/news-room/fact-sheets/detail/palliative-care

2 World Health Organisation. Palliative care, 2018. Available: https:// www.who.int/news-room/fact-sheets/detail/palliative-care

3 Together for Short Lives. What is children's palliative care. Available: https://www.togetherforshortlives.org.uk/changing-lives/supportingcare-professionals/introduction-childrens-palliative-care/

4 ICPCN. International children's palliative care network(ICPCN). The ICPCN Charter. Available: http://www.icpcn.org/icpcn-charter/

5 Milstein J. A paradigm of integrative care: healing with curing throughout life, "being with" and "doing to". J Perinatol 2005;25:563-8.

6 Sidgwick P, Fraser J, Fortune P-M, et al. Parallel planning and the paediatric critical care patient. Arch Dis Child 2019;104:994-7.
7 NICE. End of life care for infants, children and young people with life-limiting conditions: planning and management NICE guideline, 2016. Available: www.nice.org.uk/guidance/ng61

8 Section On Hospice And Palliative Medicine And Committee On Hospital Care. Pediatric palliative care and hospice care commitments, guidelines, and recommendations. Pediatrics 2013;132:966-72.

9 August WG. Palliative care (supportive and end of life care) a framework for clinical practice in perinatal medicine. BAPM 2010;44:5-11.

10 Mancini A, Uthaya S, Beardsley C. Practical guidance for the management of palliative care on neonatal units, 2014.

11 Rusalen F, Cavicchiolo ME, Lago P, et al. Perinatal palliative care: a dedicated care pathway. BMJ Support Palliat Care 2019. doi:10.1136/bmjspcare-2019-001849. [Epub ahead of print: 19 Jul 2019].

12 Reid S. Palliative care in the neonatal nursery guidelines for neonatal nurses in Australia. Available: www.pallcare.org.au

13 Balaguer A, Martín-Ancel A, Ortigoza-Escobar D, et al. The model of palliative care in the perinatal setting: a review of the literature. $B M C$ Pediatr 2012;12:25.

14 Sixty-Seventh World Health Assembly. Strengthening of palliative care as a component of comprehensive care throughout the life course, 2014.

15 den Herder-van der Eerden M, van Wijngaarden J, Payne S, et al Integrated palliative care is about professional networking rather than standardisation of care: a qualitative study with healthcare professionals in 19 integrated palliative care initiatives in five European countries. Palliat Med 2018;32:1091-102.

16 van der Eerden M, Csikos A, Busa C, et al. Experiences of patients, family and professional caregivers with integrated palliative care in Europe: protocol for an international, multicenter, prospective, mixed method study. BMC Palliat Care 2014;13:52.

17 den Herder-van der Eerden M, Ewert B, Hodiamont F, et al. Towards accessible integrated palliative care: perspectives of leaders from seven European countries on facilitators, barriers and recommendations for improvement. J Integr Care 2017;25 :222-32. vol..

18 Soni RVC, English S. A national survey of neonatal palliative care in the UK. Arch Dis Child Fetal Neonatal Ed 2011;7:162-3.

19 Kain VJ. Palliative care delivery in the NICU: what barriers do neonatal nurses face? Neonatal Netw 2006;25:387-92.

20 Guimarães DPG, Areias MHFGP, Ramalho CM. Perinatal palliative care following prenatal diagnosis of severe fetal anomaly: a new family-centered approach in a level III Portuguese Hospital. J Pediatr Neonatal Individ Med 2019;8.

21 Tosello B, Haddad G, Gire C, et al. Lethal fetal abnormalities: how to approach perinatal palliative care? J Matern Fetal Neonatal Med 2017;30:755-8.

22 Tosello B, Dany L, Bétrémieux $\mathrm{P}$, et al. Barriers in referring neonatal patients to perinatal palliative care: a French multicenter survey. PLoS One 2015;10:e0126861.

23 Mancini A, Kelly P, Bluebond-Langner M. Training neonatal staff for the future in neonatal palliative care. Semin Fetal Neonatal Med 2013;18:111-5

24 El Sayed MF, Chan M, McAllister M, et al. End-Of-Life care in Toronto neonatal intensive care units: challenges for physician trainees. Arch Dis Child Fetal Neonatal Ed 2013;98:F528-33.

25 General Medical Council. Treatment and care towards the end of life: decision making, 2016.

26 Vanhaecht K. The impact of clinical pathways on the organisation of care processes. Katholieke Universiteit Leuven, 2007.

27 Samsel C, Lechner BE. End-Of-Life care in a regional level IV neonatal intensive care unit after implementation of a palliative care initiative. J Perinatol 2015;35:223-8.

28 Draper ES, Gallimore ID. Maternal, Newborn and Infant Clinical Outcome Review Programme. In: MBRRACE-UK perinatal mortality surveillance report, 2018.

29 Breeze ACG, Lees CC, Kumar A, et al. Palliative care for prenatally diagnosed lethal fetal abnormality. Arch Dis Child Fetal Neonatal Ed 2007;92:F56-8.

30 Blakeley C, Smith DM, Johnstone ED, et al. Parental decisionmaking following a prenatal diagnosis that is lethal, life-limiting, or has long term implications for the future child and family: a metasynthesis of qualitative literature. BMC Med Ethics 2019;20:56.

31 Dekkers FHW, Go ATJI, Stapersma L, et al. Termination of pregnancy for fetal anomalies: parents' preferences for psychosocial care. Prenat Diagn 2019;39:575-87.

32 Verhagen AAE, Janvier A, Leuthner SR, et al. Categorizing neonatal deaths: a cross-cultural study in the United States, Canada, and the Netherlands. J Pediatr 2010;156:33-7. 
33 Roy R, Aladangady N, Costeloe K, et al. Decision making and modes of death in a tertiary neonatal unit. Arch Dis Child Fetal Neonatal Ed 2004;89:F527-30.

34 Aladangady N, Shaw C, Gallagher K, et al. Short-term outcome of treatment limitation discussions for newborn infants, a multicentre prospective observational cohort study. Arch Dis Child Fetal Neonatal Ed 2017;102:F104-9.

35 GOV.UK. Toolkit for high-quality neonatal services. Available: www. dh.gov.uk/en/Healthcare/Children/Earlyyears/index.htm

36 Shaw C, Stokoe E, Gallagher K, et al. Parental involvement in neonatal critical care decision-making. Sociol Health IIIn 2016;38:1217-42.

37 King NM. Transparency in neonatal intensive care. Hastings Cent Rep 1992;22:18-28.

38 Sessions WS, Kow SY, Waldrop E, et al. Breaking bad news and the importance of compassionate palliative care of the infant. Patient Exp J 2018;5:14-18
39 Hubner LM, Feldman HM, Huffman LC. Parent communication prompt to increase shared decision-making: a new intervention approach. Front Pediatr 2018;6:60.

40 Shaw C, Connabeer K, Drew $\mathrm{P}$, et al. Initiating end-of-life decisions with parents of infants receiving neonatal intensive care. Patient Educ Couns 2020;103:1351-7.

41 Linney M, Hain RDW, Wilkinson D, et al. Achieving consensus advice for paediatricians and other health professionals: on prevention, recognition and management of conflict in paediatric practice. Arch Dis Child 2019;104:413-6.

42 Meller S, Barclay S. Mediation: an approach to intractable disputes between parents and paediatricians. Arch Dis Child 2011;96:619-21.

43 The Medical Mediation Foundation. Our team. Available: https:// www.medicalmediation.org.uk/our-team/

44 Larcher V, Craig F, Bhogal K, et al. Making decisions to limit treatment in life-limiting and life-threatening conditions in children: a framework for practice. Arch Dis Child 2015;100:s1-23. 